\title{
Metabolic control of respiration and glycolysis of tumoral cells
}

\author{
Mario Gosalvez
}

Laboratorio y Servicio de Bioquímica Experimental, Clinica and Hospital Universitario Puerta de Hierro (1970-2010), Madrid and Majadahonda, Comunidad de Madrid, Spain

Email: dmg.secre@gmail.com

Received 4 December 2012; revised 5 January 2013; accepted 27 January 2013

\begin{abstract}
The contribution of the author's groups on the control of energy metabolism of cancer cells has been concisely reviewed. It is proposed that Otto Warburg's "respiratory defect" of tumoral cells resides in an alteration of the recurrent filamentation cycle of mitochondria. These give those organelles an affinity lower for ADP than the affinity of the tumor cell isoenzyme of pyruvate kinase. These two findings may explain the essentials of the intimate mechanism of the aerobic glycolysis of cancer cells.
\end{abstract}

Keywords: Energy Metabolism; Cancer; Mitochondrial Filamentation; Glycolysis; Respiration; Metabolic Control

\section{INTRODUCTION}

Over almost the past 45 years the author has dedicated a substantial part of his efforts in experimental biochemical investigation to this problem of science. He considers himself a disciple of Sydney Weinhouse and Britton Chance, two pioneer investigators in the studies of energy metabolism. This brief article covers his group's contribution to this, the last riddle of cancer's molecular physiology, without using graphs or tables, and with only a few references. Experts in this field are well versed in the contributions made by all authors in the field. However, it is arguable if the last 15 years of contributions have as yet been fully digested.

From the thousands of investigators who have devoted their lives to aerobic glycolysis and the mitochondria of tumoral cells, some third party publications, together with his own main ones, have been selected. Genetic aspects are not explored because he does not consider that sufficient experience in this area of investigation exists. The progress made in molecular genetics has been marvelous, on account of the significant funding made available over the last thirty five years due to the very worthwhile trend in cancer and genes.

\section{THE "RESPIRATORY IMPAIRMENT" OF TUMORS}

The origin of this matter which stems principally from Otto Warburg's "exhortation" in Science magazine in 1956 was countered in a fundamental way by Sydney Weinhouse, Britton Chance and Peter Pedersen, in respect of tissue sections, living cells and isolated mitochondria, respectively [1-4]. During the author's stay in Philadelphia with the first two, between April 1968 and July 1970, the basics of the issue were learned while working on mitochondria and glycolysis.

Everyone said that Warburg was partly right in certain aspects, but the tiny variations found in the respiration and glycolysis of tumors were justified, especially on account of the great fragility of the tumoral mitochondria and because of the excessive tumor enzyme indifferentiation [5].

Certainly there is a correlation between the intensity of the aerobic glycolysis and the decrease in respiration throughout the increase in the tumors' malignancy [6]. Dr. Gosalvez's group proved, first with Dr. Weinhouse, that this was due to the inability of the mitochondria to compete with ADP, which had been sequestered by the pyruvate kinase tumoral isoenzyme, the second enzyme of glycolysis which uses the ADP to phosphorylate it to ATP [7-9].

In the visit to Philadelphia he tried to ascertain whether it was possible to treat cancer by correcting the "respiratory defect" of the cancerous cell. According to the great Warburg [1], this was the cause of aerobic glycolysis in tumors, a fact that at the same time caused the indifferentiation of the tumoral cell and other primitive cells.

He familiarized himself with this theory in 1966 when, as a clinical oncologist, he had already become disillusioned with treating cancer with citoxic agents. Very malignant cancerous cells were much more resistant than normal cells to all known cellular toxics. He had experimented on this as a clinician on some head and neck, lung and ovary squamous cell carcinoma. 
Britton Chance accepted him during his postdoctoral stay in order to revisit the Warburg hypothesis, well aware that his guest was just a 27 year old clinician in anticancer chemotherapy, assistant professor in biochemistry and physics for doctors, through the reading of books. Certainly, Chance also knew, from reading his doctoral thesis, that he had only learned about tissue culture, neural microscopy and feline neurosurgery. It was a true miracle that he was taken under the wing of a world-renowned professor of Bioenergetics with such a dearth of experience in experimental biochemistry.

Chance put him into the small room, adjacent to his office, with his microfluorimeter of reduced pyridine nucleotides. Here, and among many important visitors, he was introduced by him to none other than Benno Hess, Albert Claude and Hans Krebs.

\section{EVERYONE WAS RIGHT}

Back in Madrid, in Puerta de Hierro Clinic's Experimental Biochemistry Laboratory, the problem that aroused his interest was given long and hard thought. By now, how to work on mitochondria and glycolysis had been mastered, to the highest level, and his laboratory, albeit modest, was fit-for-purpose.

The conclusion, reached in November 1970, some forty two years ago now, was that everyone was right. The experiments of the field authors, from Green to Pedersen, including Weinhouse, Chance, Weber, Gullino, and countless others of equal merit, were absolutely correct in so far as their preparatory work and conditions for experimenting. There had to be something that, by stating all were correct, furnished that "interior vision" of Otto Warburg with science's approval. To exclude the thinking of others was not correct, neither for this or any other matter, he thought on turning 30 .

Before Chance sent him off to be with Sydney, in July 1969, the problem, from the standpoint of experimental carcinogenesis, had been jointly studied by them at the Jhonson Foundation.

The mitochondrial isolation had been mechanically softened in order to test the ultimate metabolic derivative in the liver of the carcinogen amino fluorine. Dr. Gosalvez, however, considered that the mitochondrial isolation method was not very physiological for the study of pharmacological agents. The mechanical, thermic and chemical trauma, a requirement to isolate mitochondria of such purity and intensity, was huge.

Those studies were continued with the carcinogen aflatoxin and they also tried, without success, to induce cancer in rats by feeding them with rotenone food pellets, as suggested by Chance. Rotenone is a Site 1 inhibitor of the mitochondrial respiratory chain, like anaesthetic ure- thane, also cancerous, as Warburg had demonstrated.

Back in Madrid, those Philadelphia studies were further pursued, but tempering even more the mitochondrial isolation, principally by raising the temperature to $6^{\circ} \mathrm{C}$, to the point where a preparation had to be made every two hours because the mitochondrial deteriorated quickly. Most certainly they were isolated, albeit in a less pure and concentrated form, as the velocity of the differential centrifugations had also been somewhat decreased.

Furthermore, his wife, Mariflor Blanco, intubated the rats with small doses of rotenone in sunflower oil, so as to fully understand the dosage received by the animals. Using those methods they were successful, both with carcinogens as well as Rotenone Tumors [10,11].

Additionally, Dr. Weinhouse received help from Dr. Gosalvez's laboratory in matters pertaining to the competition of pyruvate kinase with mitochondrial ADP [7-9]. However they learned that the $\mathrm{Km}$ of the mitochondria for ADP was very low, $0.03 \mathrm{mM}$, while that of the pyruvate kinase was very high, $0.1 \mathrm{mM}$. Something was indeed amiss. The mitochondria had more affinity with ADP than pyruvate kinase. Why was it that that enzyme in tumors was competing favorably with the mitochondria?

Perhaps the tumoral mitochondria possessed a higher $\mathrm{Km}$ for ADP than that of its cellular pyruvate kinase. Something which might be ascertained if the mitochondria could be isolated more physiologically-perhaps, much more physiologically. As Sir Hans Krebs had once told him, this might be an impossible challenge for anyone, ever. Without becoming totally dispirited, because Sir Hans had recounted to him that Otto Warburg, his mentor, was an absolute genius, it had to be attempted, but intermittently.

\section{MITOCHONDRIAL FILAMENTATION}

Finally, between 1994 and 1999, his on-and-off insistence with this nigh on impossible task over 30 years, was crowned with success [12-14]. This was achieved with the help of some young collaborators and various other helpers who kindly shared some of their little available spare time, undoubtedly fascinated by the improbable. He was grateful for his wife's infinite patience, in dressing and undressing the mitochondria with veils, cones and filaments, to see if they would ever be able to define and correct the already proven, albeit in a preliminary way, mitochondrial filamentation defect of cancer [15-17].

Everything appears as if, in the most fundamental aspects of this field-The Metabolic Control of Respiration and Glycolysis of Tumoral Cells-the mitochondria form in their external membranes, recurrently, more intensely 
with the animal at rest, veils, cones, and short radial filaments, 25, 10 and 5 nanometres thick, which uncouples them, either intensely or partially, from the oxidative phosphorylation.

Filamented mitochondria produce oxygen while continuing to use it. Oxygen production is greater than its use near to hypoxia and is significantly lower in hyperoxia. In order to observe this, the cytoplasm must be mimicked as far as is possible in the testing medium: especially in carbon dioxide, pyridine nucleotides, ATP, ADP, phosphate, potassium and sodium.

In cancer, the process of mitochondrial filamentation would be defective. Above all, there would be a lack of filamentation and a difficulty with defilamentation. This would endow the tumoral mitochondria with a state, almost permanent, of partial filamentation. Consequently it would endow the tumoral mitochondria with a $\mathrm{Km}$ for ADP higher than that of its cellular peculiar variety of the enzyme pyruvate kinase. And, due to this, the competition for ADP between mitochondria and glycolysis would favor the latter in its second site in need of ADP to form ATP. Certainly this formation of ATP is less efficient than ADP coupling with ATP synthesis in the mitochondrial respiration.

\section{CONCLUSION}

In cancer, therefore, there would always be, more or less, depending on the tumor's malignancy, aerobic glycolysis. Due to that, patients suffer loss of weight, because of that bioenergetic inefficiency and the preferred use by the tumor's filamented mitochondria of the endogenous substrates of the Krebs' cycle.

If his group's data is analyzed fully this review would be longer and more specific on certain things, although this is not the author's style. He could be summed up as a medical doctor dedicated to investigation, one of the last remaining of the old European school: Many Thoughts from Few Experiments.

Finally, he would like to add for readers that perhaps his group, in conjunction with others, has initiated the complete understanding of Warburg's Respiratory Defect of Tumors:

A Partial Alteration of The Recurrent Filamentation-Defilamentation Cycle of Mitochondria of Tumoral Cells which Diminished the Affinity of Mitochondria for ADP below the Affinity of Their Isoenzyme of Pyruvate Kinase.

He considers beyond any doubt this will be duly concluded some years hence, by the most capable young minds of science.

\section{ACKNOWLEDGEMENTS}

M.G. is very grateful for the generous help received to his friend, neighbor and translator from Spanish into English, Mr. Andrew Guy. He is anon-scientific translator.

\section{REFERENCES}

[1] Warburg, O. (1956) On the origin of cancer cells. Science, 123, 309-314. doi:10.1126/science.123.3191.309

[2] Weinhouse, S. (1956) Oxidative metabolism of neoplastic tissues. Advances in Cancer Research, 3, 269-315. doi:10.1016/S0065-230X(08)60922-7

[3] Chance, B. and Hess, B. (1959) Spectroscopic evidence of metabolic control. Science, 129, 700-708. doi:10.1126/science.129.3350.700

[4] Pedersen, P.L, Grienwalt, J.W., Chan, T.L. and Morris, HP. (1970) A comparison of some ultrastructural and biochemical properties of mitochondria from Morris Hepatomas. Cancer Research, 30, 2620-2626.

[5] Aisemberg, A.C. (1961) The glycolysis and respiration of tumors. Academic Press, New York.

[6] Lo, C.H., Cristofalo, V.J., Morris, H.P. and Weinhouse, S. (1968) Studies on respiration and glycolysis in transplanted tumors of the rat. Cancer Research, 28, 1-10.

[7] Weinhouse, S. (1972) Glycolysis, respiration and anomalous gene expression in experimental hepatomas. Cancer Research, 32, 2007-2010.

[8] Gosalvez, M., Lopez-Alarcon, L., Garcia-Suarez, S., Montalvo, A and Weinhouse, S. (1975) Stimulation of tumor-cell respiration by inhibitors of pyruvate kinase. European Journal of Biochemistry, 46, 133-140. doi:10.1111/j.1432-1033.1974.tb03605.x

[9] Gosalvez, M., Garcia Suarez S. and Lopez Alarcón, L. (1978) Metabolic control of glycolysis in normal and tumor "permeabilized" cells. Cancer Research, 38, 142-148.

[10] Gosalvez, M. and Perez-Garcia, J. (1971) Action of chemical carcinogens on electrón transport and energy in isolated mitochondria. Proceedings 7th FEBS Meeting, Varna, No. 621, 232.

[11] Gosálvez, M., Díaz-Gil, J., Coloma, J. and Salganicoff, L. (1977) Spectral and metabolic characteristics of mitochondrial fractions from rotenone-induced tumours. British Journal of Cancer, 36, 243-253. doi:10.1038/bjc.1977.184

[12] Gosalvez, M., Blanco, M., Testillano, P.S. and Risueño, M.C. (1996) Warm low stress isolated filamentous mitochondria. Cellular and Molecular Biology, 42, Abstract 4.

[13] Gosalvez, M. and Blanco, M. (1998) Oxygen production by filamentous mitochondria. Proceedings of Abstract ISOTT'98, Budapest, Abstract 08.

[14] Gosálvez, M. (1998) Producción de oxígeno por mitocondrias filamentadas. Importancia para el cáncer y la neurodegeneración. Anales de la Real Academia Nacional de Medicina, Tomo CXV, Cuaderno Tercero, 747756.

[15] Gosalvez, M. (2010) Mitochondrial filamentation. Proceedings 110th Meeting, AACR, Washington, 76, 20.

[16] Gosalvez, M. (2012) Reversal of cancer by dual strategy: 
A new molecular target? Proceedings 103rd AACR Meeting, Chicago, 31 March-4 April 2012, Abstract 4611, 1118.
[17] Gosalvez, M. (2012) Mitochondrial filamentation: Some Methods of isolation and assay. IORS Journal of Pharmacy and Biological Sciences, 4, 37-39. 